\title{
Effects of EGFR, CK19, CK20 and Survinin Gene Expression on Radiotherapy Results in Patients with Locally Advanced Head and Neck Cancer
}

\author{
Kezban Esra Kekilli', Candan Demioz Abakay ${ }^{2}$, Gulcin Tezcan ${ }^{3}$, Berrin Tunca ${ }^{3}$, \\ Unal Egeli ${ }^{3}$, Ozlem Saraydaroglu ${ }^{4}$, Onur Esbah ${ }^{5 *}$, Ahmet Siyar Ekinci ${ }^{5}$, Sonay \\ Arslan $^{6}$, Nuri Uslu ${ }^{6}$, Lutfi Ozkan²
}

\begin{abstract}
Purpose: To investigate the effects of epidermal growth factor receptor (EGFR), cytokeratin 19 (CK19), cytokeratin 20 (CK20) and survinin gene expression on local control (LC) and overall survival (OS) in patients with locally advanced head and neck cancer (LAHNC) who were administered radiotherapy (RT). Materials and Methods: Twenty-six patients who were admitted to Uludag University Medical Faculty Department of Radiation Oncology with a diagnosis of LAHNC (GIII-GIV) were included in this study. Gene expression was evaluated in tumor tissues and peripheral blood. RNA isolation was performed on paraffinized tumor tissues and peripheral blood samples obtained before RT (BR). The densities of the obtained RNAs were analyzed at $260 / 280 \mathrm{~nm}$. cDNA samples obtained from total RNA,EGFR, CK19, CK20 and survinin gene expression levels were assessed via the Sybr Green method and data were analyzed with the $\Delta \Delta \mathrm{Ct}$ method. The same process was repeated for peripheral blood samples taken after RT (AR). Results: The female/male ratio was 3:23 and the mean age was 56.5 years (38-75years). After radiotherapy, CK19 and CK20 levels in the peripheral blood were found to be correlated according to Pearson correlation analysis $(p=0.049)$. This result indicates a possibility of remaining positive for CK19 and CK20 in the peripheral blood even after RT in patients with CK19, CK20, and EGFR positive tumors before RT. There was a statistically significant correlation between survinin levels measured BR and AR ( $p=0.028)$. Conclusions: In this study, we found that patients with any EGFR, CK19, CK20 or survinin positivity in their peripheral blood obtain less benefit from radiotherapy. A wider patient population and advanced protein analyses are necessary in order to increase the reliability of our findings.
\end{abstract}

Keywords: Locally advanced head and neck cancer - EGFR - CK19 - CK20 - survinin - gene expression - radiotherapy

Asian Pac J Cancer Prev, 16 (7), 3023-3027

\section{Introduction}

Approximately $60 \%$ of all head and neck cancer(HNC) cases are diagnosed as locally advanced stage disease (Forastiere et al., 2008; Cooper et al., 2009). The primary goal is to increase the survival rate and protect organ functionality in the treatment of locally advanced head and neck cancer(LAHNC). The reason for achieving different results by applying similar treatment methods to tumors localized at the same area, at the same stage and sharing similar histopathologic characteristics may be the existence of cells with undefined predictive features that are resistant to the current treatment. Comprehensive studies conducted in order to predict radiosensitivity and radioresistance revealed that EGFR expression indicates a bad prognosis and resistance to cytotoxic agents including radiation in LAHNC (Zimmerman et al., 2006).

Khan et al. (2010) stated that survinin expression is related toradiotherapy resistance and can be used as a marker for identifying oral squamous cell carcinoma (OSCC) patients who can benefit from RT. An intermediate filament protein called CK19 was detected in the bone marrow in two studies assessing HNC patients. CK19 expression was attributed to disease progression and local relapse (Andratschke et al., 2003; Wollenberg et al., 2004). CK20 expression detected in advanced OSCC cases was attributed to tumor diameter. It was also indicated that the existence of CK20mRNA can be used as a marker for relapse in oral cancers. In this study, we investigated the prognostic and predictive roles of EGFR, CK19, CK20 and survinin expression measured by RT-PCR before and after radiotherapy in patients with LAHNC. 


\section{Materials and Methods}

\section{Patients and samples}

Twenty-six patients with locally advanced (Stage III-IV) HNC who were admitted to Uludağ University Medical Faculty Department of Radiation Oncology and underwent chemo-radiotherapy were investigated in terms of the parameters that play a role in OS and DFS.

All cases provided informed constant including information about genetic studies. EGFR, CK19 and CK20 gene expression was assessed on all tumor and normal tissue samples which were taken during surgery and storedin paraffin after histological and pathological examinations. Increased and normal expression of EGFR, CK19 and CK20 in tumor tissue was considered positive. Peripheral blood samples were examined for EGFR, CK19, CK20 and survinin expression via RT-PCR before RT and three months after RT; any value above 0 was considered positive for EGFR, CK19 and CK20, while values above 0.2 were considered positive for survinin expression.

\section{RT-PCR analysis}

Tumor and normal tissues embedded in paraffin were treated with BIOstic (MO BIO Laboratories, Carlsbad, CA) and washed with $100 \%$ ethanol. The RNeasy FFPE Kit (QIAGEN, Germantown, Maryland, USA) was used for RNA isolation from deparaffinized tissue samples. Lymphocyte isolation was performed by washing peripheral blood samples with red blood cell lysis buffer (Roche Diagnostics, Mannheim, Germany) and total RNA isolation was performed with the High Pure RNA Isolation Kit (Roche Diagnostics). The density and purity of the RNA samples was measured by NanoDrop 2000 spectrophotometry (Thermo Scientific, Wilmington, Delaware, USA). RNA samples with $\sim 1.8$ as the OD260/ OD280 optical density and with a concentration of $200-400 \mathrm{ng} / \mu 1$ were chosen. The RT2 First Strand Kit (SABioscience) was used for cDNA synthesis from extracted RNAs; $5 \mu \mathrm{g}$ of RNA was used for each cDNA synthesis. cDNA synthesis consisted of two phases: in the first phase, a mixture of 2-8 $\mu 1 \mathrm{RNA}, 2 \mu \mathrm{l} \mathrm{GE}$ and6-0 $\mu \mathrm{L}$ $\mathrm{H} 20$ was placed in the thermocycler for 5 minutes at $42^{\circ} \mathrm{C}$ and afterwards placed on ice for 1 minute. In the second phase, a mixture of $4 \mu 1 \mathrm{BC} 3,1 \mu 1 \mathrm{P} 2,2 \mu 1 \mathrm{RE} 3$ and 3 $\mu 1 \mathrm{H} 2 \mathrm{O}$ was added to the first mixture and kept at $42^{\circ} \mathrm{C}$ for 15 minutes and $95^{\circ} \mathrm{C}$ for 5 minutes (abbreviations: GE:5X gDNA Elimination Buffer, BC3: 5X Reverse Transcriptase Buffer 3, $\mathrm{H}_{2} \mathrm{O}$ : RNAse-free $\mathrm{H} 2 \mathrm{O}, \mathrm{P} 2$ : Primer and External Control Mixture, RE3: Reverse Transcriptase Enzyme Mixture 3). mRNA levels of peripheral blood and tumor samples were measured via specific primers for EGFR, survinin, CK19 and CK20 by applying them to the extracted cDNA samples. A mixture of $1 \mu 1$ of the primers, $12.5 \mu 1$ RT2 PCR Sybr Green Master Mix, $1 \mu 1$ cDNA and $10.5 \mu 1 \mathrm{ddH} 2 \mathrm{O}$ was distributed in a96-well plate. The PCR process took place in an LC 480 device. In the denaturation phase of the PCR, the sample was heldfor 10 minutes for onecycle at $95^{\circ} \mathrm{C}$, and in the amplification phase the sample was held at $95^{\circ} \mathrm{C}$ for 15 seconds for 40 cycles (a single fluorescent reading was performed at $72^{\circ} \mathrm{C}$ ) and held at $60^{\circ} \mathrm{C}$ for 1 minute. Constant reading was performed during the melting curve $\left(95^{\circ} \mathrm{C}\right.$ to $\left.65^{\circ} \mathrm{C}\right)$. The $\Delta \triangle \mathrm{CT}$ method was used for the comparison of normal and tumor tissue expression results.

\section{Radiotherapy}

In the RT plan, bilateral parallel areas were irradiated with $1.8-2 \mathrm{~Gy} / \mathrm{fx}$ dose with a $6 \mathrm{MV}$ photon beam until 46 Gy and completed to 50 Gy following spinal cord protection. The protected side of the posterior neck was also completed to $50 \mathrm{~Gy}$ with the appropriate energy level electrons. In definitive RT/radio-chemotherapy following $50 \mathrm{~Gy}$,the primary tumor and the surrounding $2 \mathrm{~cm}$ area was increased to 63-75 Gy (total dose was 60-67 Gy in postoperative patients) and left at $50 \mathrm{~Gy}$ if there was no lymph node involvement. In cases of involved lymph nodes $<3 \mathrm{~cm}$, an additional dose (boost) was applied and completed to 60-66 Gy. The anterior area (supraclavicular area) was left at $46 \mathrm{~Gy}$.

\section{Statistics}

SPSS16.0 (Statistical Package for the Social Sciences, Chicago, IL) was used for the statistical analysis. The Shapiro-Wilk test was used for the assessment of a normal distribution. The Mann-Whitney U test was used for the comparison of two groups with a non-normal distribution. The Wilcoxon signed rank test was used in order to compare paired samples. Pearson correlation and Spearman correlation coefficients were used on the expression of all markers BR and AR in both peripheral blood and tumor tissue samples. Fisher's exact chi-square test was used in the assessment of categorical data and for the comparison of circulating gene expression in the peripheral blood BR and AR. Survival analysis of univariate analysis was performed with the log-rank test via the Kaplan-Meier method. Cox regression analysis was used in the assessment of prognostic factors that may affect OS and DFS in multivariate analysis. $\mathrm{p}<0.05$ was considered statically significant in all analyses.

\section{Results}

The demographic, clinical and histopathological characteristics of the cases are summarized in Table 1. The mean follow-up period was 18 months (3-26 months). During the follow-up period, progression was observed in primary tumors of seven cases (five larynx and two other tumors) and metastases were observed in six cases (two larynx, one maxillary and three nasopharynx cases).

EGFR, CK19, CK20 and survinin expression detected by RT-PCR was as follows in blood samples taken before radiotherapy (BR): six cases (23.1\%), four cases (15.4\%), one case (3.8\%) and one case (3.8\%), respectively. One case was positive for EGFR, three cases were positive for CK19 and four cases were positive for CK20 three months after RT, while there were no cases positive for survinin expression. Tumor tissues of 17 cases were analyzed for expression and five cases (19.5\%) were positive for EGFR, eight cases (30.8\%) were positive for CK19 and one case (3.8\%) was positive for CK20 expression. The Spearman correlation test was performed and there was no 
EGFR, CK19, CK20 and Survinin Genes Expression and Radiotherapy for Locally Advanced Head and Neck Cancer Table 1. Demographic, Clinical and Histopathological Characteristics of the Patients

\begin{tabular}{|c|c|c|c|c|c|c|c|}
\hline Characteristics & Number $(\%)$ & Characteristics & Number $(\%)$ & Characteristics & Number $(\%)$ & Characteristics & Number $(\%)$ \\
\hline \multirow{4}{*}{$\begin{array}{l}\text { Operated } \\
\text { curative }\end{array}$} & $10(38.5)$ & Mortality & & \multicolumn{2}{|l|}{ NeoadjuvantCT } & \multicolumn{2}{|c|}{ Disease progression } \\
\hline & $16(61.5)$ & Yes & - & Yes & $7(26.9)$ & Yes & $6(23.1)$ \\
\hline & & No & $9(34.6)$ & No & $2(7.7)$ & No & $20(76.9)$ \\
\hline & & Unknown & $17(65.4)$ & Unknown & $17(65.4)$ & & \\
\hline \multicolumn{2}{|l|}{ Histopathological } & Grade & & \multicolumn{2}{|l|}{ Metastasis } & \multicolumn{2}{|c|}{ Salvation surgery } \\
\hline $\mathrm{SCC}$ & $19(73.1)$ & Well differentiated & $2(7.7)$ & Yes & $6(23.1)$ & Yes & $2(7.7)$ \\
\hline Adenoid cystic & $2(7.7)$ & $\begin{array}{l}\text { Moderately } \\
\text { differentiated }\end{array}$ & $11(42.3)$ & No & $20(76.9)$ & No & $24(92.3)$ \\
\hline \multirow[t]{3}{*}{ Undifferentiated } & \multirow[t]{3}{*}{$5(19.2)$} & Poor differentiated & $10(38.5)$ & & & & \\
\hline & & Adenoid cystic & $2(7.7)$ & & & & \\
\hline & & Unknown & $1(3.8)$ & & & & \\
\hline \multicolumn{2}{|l|}{ Primary location } & \multicolumn{2}{|l|}{ Tumor diameter } & \multicolumn{2}{|l|}{ CT after RT } & \multicolumn{2}{|c|}{ Tumor progression } \\
\hline Larynx & $10(38.5)$ & $4>$ & $3(11.5)$ & Yes & $10(38.5)$ & Yes & $7(26.9)$ \\
\hline \multirow[t]{2}{*}{ Other } & $16(61.5)$ & $4<$ & $6(23.1)$ & No & $16(61.5)$ & No & $19(73.1)$ \\
\hline & & Unknown & $17(65.4)$ & & & & \\
\hline PNI & & T Stage & & Stage & & Age & \\
\hline Yes & $6(23.1)$ & 2 & $2(7.7)$ & 3 & $6(23.1)$ & $40<$ & 25 \\
\hline No & $4(15.4)$ & 3 & $9(34.6)$ & 4 & 20 (76.9) & $40>$ & 1 \\
\hline \multirow[t]{2}{*}{ Unknown } & $16(61.5)$ & 4 & $14(53.8)$ & & & & \\
\hline & & Unknown & $1(96.2)$ & & & & \\
\hline LVI & & N Stage & & Gender & & & \\
\hline Yes & - & 0 & $10(38.5)$ & Female & $3(11.5)$ & & \\
\hline No & $9(34.6)$ & 1 & $4(15.4)$ & Male & $23(88.5)$ & & \\
\hline \multirow[t]{2}{*}{ Unknown } & $17(65.4)$ & 2 & $10(38.5)$ & & & & \\
\hline & & 3 & $2(7.7)$ & & & & \\
\hline
\end{tabular}

Table 2. Correlation Analysis of Gene Expression in Peripheral Blood after Radiotherapy

\begin{tabular}{lcl}
\hline Assessed Genes & Pearson Correlation & \multicolumn{1}{c}{$\mathrm{p}$} \\
\hline EGFR and CK19 & -0.061 & 0.776 \\
EGFR and CK20 & -0.065 & 0.764 \\
EGFR and Survivin & -0.134 & 0.533 \\
CK19 and CK20 & $0.407 *$ & 0.049 \\
CK19 and Survivin & -0.113 & 0.6 \\
CK20 and Survivin & 0.04 & 0.853 \\
\hline
\end{tabular}

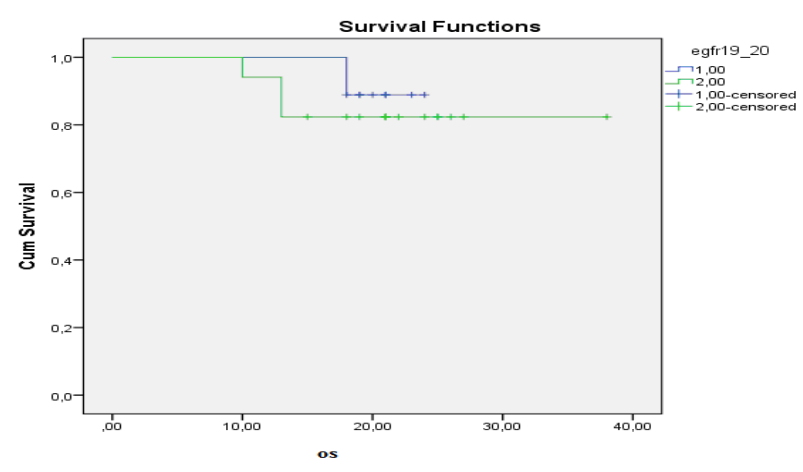

statistically significant correlation between EGFR, CK19, CK20 and survinin expression measured in tumor tissue before and after radiotherapy. According to the Pearson correlation test, there were no statistically significant correlations between gene expression levels measured BR.

There was no AR EGFR expression, while there were five cases positive for EGFR in tumor tissues BR $(\mathrm{p}=0.068)$. The lack of statistical significance in this issue is attributed to the small size of the study group. There was a statistically significant difference between survinin levels measured BR and AR ( $\mathrm{p}=0.028)$. Positivity for EGFR, CK19, CK20 and survinin expression in peripheral blood and tumor samples did not affect OS according to the log-rank analysis (Figure 1).

AR CK19 and CK20 levels in peripheral blood were found to be correlated ( $\mathrm{p}=0.049)$ (Table 2). It was observed that 22 cases $(84.6 \%$ ) were alive and four cases $(15.4 \%)$ resulted in mortality at the date of assessment in September 2012. Mean OS was calculated as 19 months (10-38) and mean DFS was calculated as 20 months (3-24). It was noted that the mortalities occurred due to LAHNC. There were no statistically significant clinical, pathological, molecular or treatment-related parameters that affected OS and DFS.

OS was not affected by AR chemotherapy ( $\mathrm{p}=0.083)$,

Figure 1. Relationship between EGFR, CK19 and CK20 with OS before RT assessed via the log-rank test $(p=0.618)$

while a statistically significant difference was observed in the DFS rates of tumors localized in the larynx in patients with AR chemotherapy $(\mathrm{p}=0.013)(24$ months and 21 months). A significant risk factor could not be defined for OS and DFS with the Cox regression analysis.

\section{Discussion}

The current standard treatment methods of LAHNC are surgery, chemo-radiotherapy and/or cetuximab (Lin et al., 2004). The different results achieved by applying similar treatment methods to the same stage and localized tumors has led to defining prognostic and predictive factors that may affect treatment methods. Thus, the comprehensiveness of the studies conducted in this area is widened. Unnecessary RT treatments will be prevented byidentifying RT resistant cases (Venook, 2005). Additionally, with defining some parameters that may predict metastases, more aggressive treatment 
methods can be used at the beginning of therapy. There are several recent studies asserting that the existence of EGFR gene expression can be used as a marker for metastasis in several tumor types (Tunca et al., 2012). Furthermore, there are other studies indicating that CK19, CK20 and survinin gene expression levels are increased in metastatic tumor cells found in the peripheral blood (Zhao et al., 2011). There have been no prior studies assessing EGFR, CK19, CK20 and survinin gene expression levels in the Turkish population.

In this study, we investigated the effects of EGFR, CK19, CK20 and survinin gene expression in tumor and normal tissue samples taken BR and peripheral blood samples taken both BR and AR on the benefits obtained with radiotherapy. Only $15.3 \%$ of cases investigated for EGFR expression levels in tumor tissues were positive. $75 \%$ of EGFR expression positive cases responded to therapy. 54\% of patients without EGFR expression underwent therapy. Hence, the EGFR mutation was observed in only a small portion of patients achieving different results with treatment than in patients without EGFR expression. This gave rise to the thought that there may be EGFR mutations in tumor cells in some cases. In order to make a reliable statistical assessment about the effects of radiotherapy combined with cetuximab in patients with EGFR expression positive HNC, the number of patients included in this study should be increased. Also, the existence of EGFR gene mutations must be assessed in EGFR expression negative patients. In the assessment of EGFR expression in peripheral blood samples taken both BR and AR, we observed EGFR expression in $18.5 \%$ of patients. There was no EGFR expression in the peripheral blood samples of AR patients. Thus, we can assert that the possibility of metastasis can be reduced with RT in patients with increased EGFR expression.

The expression of the cytokeratin (CK) family is related to metastatic potential in several cancer types (Yang et al., 2010; Tunca et al., 2012; Shimada et al., 2012). In two of three studies assessing the effects of CK19 gene expression on $\mathrm{HNC}$, it was stated that the expression of CK19 in bone marrow cells is related to relapse and metastasis (Andratschke et al., 2003; Wollenberg et al., 2004). Zhang et al. (2007) also indicated that increased CK expression in locally advanced OSCC cases is related to tumor relapse and decreased survival. CK19 expression was observed in $15.3 \%$ of patients in peripheral blood samples BR and it was found to be down regulated in all of these cases. Furthermore, CK19 expression was observed in the tumor tissues of two cases with laryngeal cancer that developed metastases. According to our findings, CK19 expression in the peripheral blood can be reduced by RT, and CK19 positivity may be related to metastasis risk in patients with laryngeal cancer. However, in order to make a reliable and statistically significant conclusion, the patient number included in this study should be increased.

In a recent study by Tunca et al., it was indicated that CK20 expression in the peripheral blood is related to metastasis and relapse in patients with breast cancer (Tunca et al., 2012). Toyoshima et al. stated that increased CK20 expression in peripheral blood is related to tumor diameter (Toyoshima et al., 2009). CK20 expression was observed $3.8 \%$ of our cases and this proportion was found to increase AR. Thus, we assert that CK20 expression cannot be inhibited by RT. Furthermore, when assessing EGFR, CK19 and CK20 expression levels together, AR positivity of CK19 and CK20 was found to be related by Pearson correlation analysis $(\mathrm{p}=0.049)$. Thus, it can be stated that CK19 andCK20 positivity continues even after RT in patients with CK19, CK20 and EGFR positive tumor tissue and peripheral blood samples BR.

It is a well-known fact that survinin is an anti-apoptotic gene that is expressed in several cancer types, including $\mathrm{HNC}$, and is related to tumor aggressiveness and drug resistance (Khan et al., 2010; Zhu et al., 2011). In a study by Khan et al. (2010) it was indicated that increased survinin expression in patients with HNC is correlated with clinical stage, metastasis and OS, and plays role in RT resistance. In a study assessing the relationships of 70 different proteins between before and after radiotherapy via ELISA in HNC cases, it was found that only survinin could be used as a marker for radiotherapy sensitivity in HNC patients (Farnebo et al., 2011). We also found that survinin expression levels taken $\mathrm{BR}$ and $\mathrm{AR}$ were correlated $(\mathrm{p}=0.028)$. These results indicate potential resistance to RT in patients with increased survinin expression in the peripheral blood.

As a conclusion, in order to increase the reliability of our study, the number of patients included in the study must be increased, and our findings should be confirmed with advanced protein analysis. Nevertheless, we can assert that HNC patients with positive gene expression for any of EGFR, CK19, CK20 and survinin get less benefit from RT.

In our study, EGFR, CK19, CK20 and survinin expression was not correlated with OS when they were assessed independently. Other studies conducted in order to assess the relationship between the metastatic potential of HNC and EGFR, CK19 andCK20 expression have been inadequate. In order to determine the potential benefits of RT in patients with HNC, new studies are necessary to examineother metastasis markers together with the genes investigated here both BR and AR.

\section{References}

Andratschke M, Pauli C, Stein M, et al (2003). MHC-class I antigen expression on micrometastases in bone marrow of patients with head and neck squamous cell cancer. Anticancer Res, 23, 1467-71.

Cooper JS, Porter K, Malin K (2009). National cancer database report on cancer of the head and neck:10 year update Head Neck. DETAILS??

Farnebo L, Jerhammar F, Ceder R, et al (2011). Combining factors on protein and gene level to predict radioresponse in head and neck cancer cell lines. J Oral Pathol Med, 40, 739-46.

Forastiere AA, Ang KK, Brizel D, et al (2008). National comprehensive cancer network, head and neck cancers. $J$ Natl Compr Canc Netw, 646-95

Khan Z, Khan N, Tiwari RP, et al (2010). Down-regulation of survivin by oxaliplatin diminishes radioresistance of head and neck squamous carcinoma cells. Radiother Oncol, 96, 267-73. 
Lin JC, Wang WY, Chen KY, et al (2004). Quantification of plasma Epstein-Barr virus DNA in patients with advanced nasopharyngeal carcinoma. $N$ Engl J Med, 350, 2461-70.

ToyoshimaT, Vairaktaris E, Nkenke E, et al (2009). Hematogenous cytokeratin 20 mRNA Detection has prognostic impact in oral sguamous cell carsinoma. preliminary results. Anticancer Res, 29, 291-97.

Tunca B, Egeli U, Cecener G, et al (2012). CK19, CK20, EGFR and HER2 status of circulating tumor cells in patients with breast cancer. Tumori, 98, 243-51.

Shimada R, Iinuma H, Akahane T, et al (2012). Prognostic significance of CTCs and CSCs of tumor drainage vein blood in Dukes' stage B and C colorectal cancer patients. Oncol Rep, 27, 947-53.

Venook AP (2005). Epidermal growth factor receptor-targeted treatment for advanced colorectal carcinoma. Cancer, 103, 2435-46.

Wollenberg B, Walz A, Kolbow K, et al (2004). Clinical relevance of circulating tumour cells in the bone marrow of patients with SCCHN. Onkologie, 27, 358-62.

Yang RN, Yang SH, Chang CC, et al (2010). Upregulation of fecal cytokeratin 19 is associated with prognosis in older colorectal cancer patients. Genet Test Mol Biomarkers, 14, 703-08.

Zhao S, Liu Y, Zhang Q, et al (2011). The prognostic role of circulating tumor cells (CTCs) detected by RT-PCR in breast cancer: a meta-analysis of published literature. Breast Cancer Res Treat, 130, 809-16.

Zhong LP, Chen WT, Zhang CP, et al (2007). Increased CK19 expression correlated with pathologic differantiation grade and prognosis in oral sguamous cell carcinoma patients. Oral Surg Oral Pathol Oral Radiol Endod, 104, 377-84

Zhu H, Wang Q, Hu C, et al (2011). High expression of survivin predicts poor prognosis in esophageal squamous cell carcinoma following radiotherapy. Tumour Biol, 32, 1147-53.

Zimmerman M, Zauhair A, Ozsahin M (2006). The epidermal growth factor reseptor (EGFR) in head and neck cancer its role and treatment implications, Radiat Oncol, 1, 11. 